\title{
The Research on Weijiadi Coal Mine Safety Quality Standardization System Construction
}

\author{
Ju-Feng Zhang, Bing Liu, \\ Feng-Feng Yang,Chao Zheng \\ College of Energy Engineering, \\ Longdong University, \\ Qingyang, China \\ E-mail: jufeng6100229@126.com
}

\author{
Zai-Quan Miao, Jian-Jiang Zhang, \\ Rui-Yun Wang \\ Weijiadi coal mine, \\ Jingyuan Coal Industry Group Co., Ltd, \\ Baiyin, China \\ E-mail: 422622510@qq.com
}

\begin{abstract}
Safety is the premise and foundation of coal mine production, it is the bottleneck that restricts the sustainable development of the mine, and how to do a good job of coal mine safety has become the focus of scientific and technical workers. Coal mine safety quality standardization work is the foundation of work safety, on the basis of coal mine safety quality standardization construction development and the process of cognition, this paper expounds the relationship between coal mine safety and quality standards and production safety. By applying the Deming principle, Weijiadi coal mine establishes safety quality standardization system which is horizontal to edge and vertical in the end, the goal was achieved within five years.
\end{abstract}

Keywords-Coal mine safety; quality standard; Deming principle; system construction

\section{INTRODUCTION}

Coal mine safety quality standardization is management model of enterprise's self restriction, self improvement and self perfection, not only can enable workers to enhance safety awareness and safety behavior, to enhance the overall quality of staff, but also it is of great significance to strengthen safety production and the essential safety management of mine, in order to make the coal develop well in the long time and ensure the miner's life safety and modernization of coal mine, we must accelerate the implementation process of coal mine safety quality standardization[1-3].

Coal mine safety quality standardization work has gone through nearly 40 years of history from the exploration to the present in China. Generally speaking, it experienced four stages, which is, in the mid 1960s to 1985 the initial stage of exploration, 1986 - 1992 years guide and start the development stage, from 1993 to 1997 years of comprehensive development and achieved remarkable results stage and in 1998 so far adapt to new situations, new progress has been made in the stage. In the initial exploration stage, in order to adjust the pumping, digging, mining problems, recovery and improve production capacity, to ensure the supply of coal, most of the coal mine safety quality standardization work has not mentioned important agenda. Until 1986, the former Ministry of coal requirements of coal mines across the country to carry out quality standards, safety record activity levels, ", stressed the need to pay close attention to project quality, ensure safety in production, in Feicheng Mining Bureau held the first national coal quality standard spot, to set off vigorously quality standard boom, the coal enterprises establish and improve the safe production responsibility system, clearly defined enterprise party is mainly responsible for the standardization work of person of the first responsibility, make the safety quality standardization work planning. National Coal Mine Safety Supervision Bureau was established, in order to strengthen the coal mine safety production base, the introduction of the "safety production law", "Coal Mine Safety Supervision Regulations", "coal mine safety regulations" and the coal mine safety production basic requirements "and other laws and regulations, strict mine safety access conditions and improve the ore standard, provides the legal basis for the in-depth development of coal mine safety quality standardization work. At the same time, through the implementation of small coal mines shut down and coal mine safety production special reorganization of activities, illegal mining, illegal production phenomenon has been effectively curbed, for the coal enterprises to carry out quality standardization work to create a favorable environment.

\section{WEIJIADI COAL MINE SAFETY QUALITY STANDARDIZATION CONSTRUCTION}

\section{A. Weijiadi Coal Mine Safety Quality Standardization Construction of the Guiding Ideology and Basic Principle}

\section{(1) Introduction of Weijiadi coal mine}

Weijiadi coal mine is the backbone of mine of Gansu Jingyuan Coal and Electricity Co., Ltd., the production capacity was approved as 3 million tons in 2015 , also is coal and coal-bed methane dual energy efficient mine in Gansu Province, and it has five serious natural disasters, was one of 35 seat safety focus of mine in the national coal system. In recent years, the mine conscientiously implement the national safety guidelines, put safety in the first place, production is not at the expense of human life. To prevent serious accidents, it always adhere to the management model of "management, equipment, training, the cultural", the mine has been safely produced more than 2000 days. 


\section{(2) Guiding ideology}

Under the guidance of "safety first, prevention first, comprehensive treatment", "coal mine safety regulations" and "coal mine safety quality standardization of basic requirements and grading method" are as the standard, the coal mine adheres to the people-oriented, scientific development, innovation management principles, fine management and performance appraisal are as the starting point, the formation of transverse to the edge, the flat management of horizontal to edge, vertical in the end is basically formed, fine management and quality standard of organic integration has been realized, and raise the overall level of mine safety and quality standardization, as shown in figure 1:

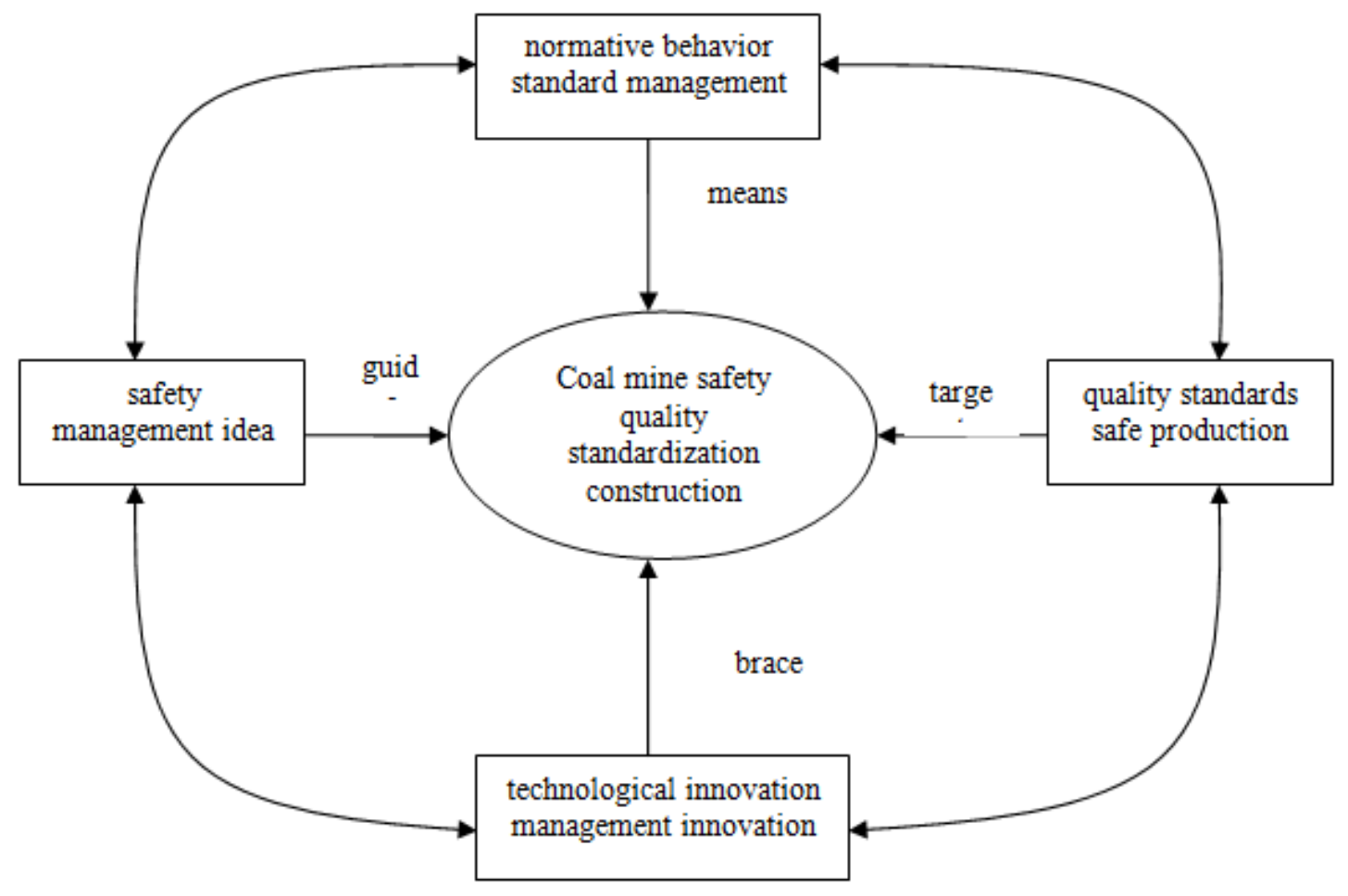

Figure.1. the structure diagram of safety quality standardization construction idea

\section{(3) The basic principle - Deming model}

The safety quality standardization system is a systematic "Deming model"[4-7], as shown in Figure 2, PDCA model. The model is composed of "plan, do, check, act", which enterprises improve and perfect a dynamic drive management pattern. Through the PDCA cycle advancing, it can make the enterprise realize the benefit, safety step promotion effect in the production process.

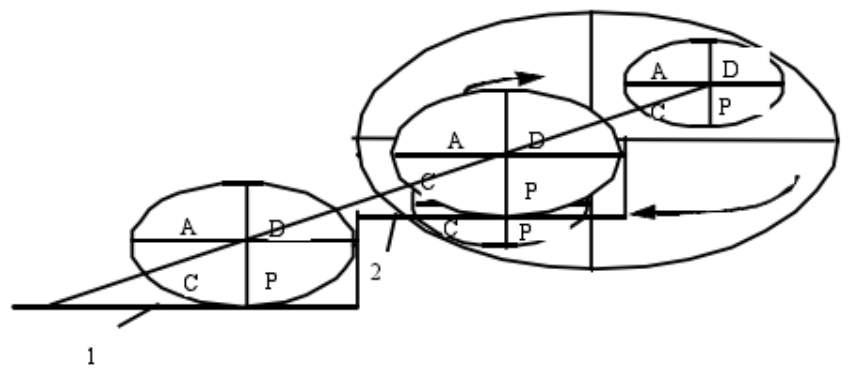

Figure.2.

"Deming model" of safety quality standardization system
The characteristics of the model: safety quality standardization of various professional (or elements) will be a PDCA cycle, through the interlocking ring loop drive forward, upward, promotes the upward development of the whole system. In the Deming cycle, in general, the development of the entire system is through the various subsystems, one level to promote the implementation of the. II each subsystem of PDCA cycle, have their respective objectives and content, not round and round in situ real turnover, but stepped up development, safety and quality standards of after each PDCA cycle will solve a cycle by cycle problem (or hidden) and the standardization level of overall quality will rise a step. In the PDCA cycle, a (improvement or implementation) is the key to improve the quality of safety standards.

Safety management is a systematic project, if the management is seen as the size of the different gears, core big gear drive and force, all different gear follow cooperation operation, PDCA cycle is implemented. 


\section{B. The Application of PDCA Cycle Model in the Construction of Weijiadi Coal Mine Safety Quality Standardization}

(1) Plan. In accordance with the "Weijiadi coal mine safety quality standardization work plan of 12th Five-Year", which is standing on the starting point to seek better development, standing in a higher position to advance, and achieving the "three standard" in five years, namely the benchmarking with the most advanced mine of Jingyuan Coal Group Corporation, benchmarking with the most advanced mine of Gansu Province, and benchmarking with the most advanced mine of the China, makes mine quality standardization to a new level. Through annual plan and quarterly plans, the day theme, every month promotion policy, the manager responsibility system, and special rectification activities regularly carried out in various forms, the safety quality standardization develops well.

(2) Do. According to different majors, safety quality standardization construction work is carried out decomposition. And through the form of safety quality standardization in each quarter, the sense of responsibility and mission of the staff and workers have been strengthened, the stage goal has been achieved, which continues to advance the development of quality standardization, so as to achieve the overall goal of the struggle.

(3)Check. According to different majors, ventilation quality standard check list, quality standard check lists of coal mining and heading, and quality standard check lists of mechanical and transport are compiled, and the investigation of professional security risks and safety quality standardization inspection are regularly carried out.

(4) Act. In order to be responsible for the unit to correct the error, hidden dangers and problems which professional and technical personnel to find out must be ways to correct. At the same time, safety supervision department, ground traffic information center were as two closed-loop management center, who implement management tasks of hidden problem elimination record.

\section{CONSTRUCTION OF MINE SAFETY QUALITY STANDARDIZATION WORK SYSTEM}

On the basis of the whole party, government, and common management of the group, Weijiadi coal mine achieved good results, that the mine products safely more than 2000 days, but $t$ there is still a certain gap compared with the most advanced mine in the China. Therefore, in order to lay a solid foundation for safety and realize the sustainable development of mine, we must strengthen the safety quality standard construction. Through the implementation of flat management, mine safety quality standardization system is established, as shown in Figure 3.

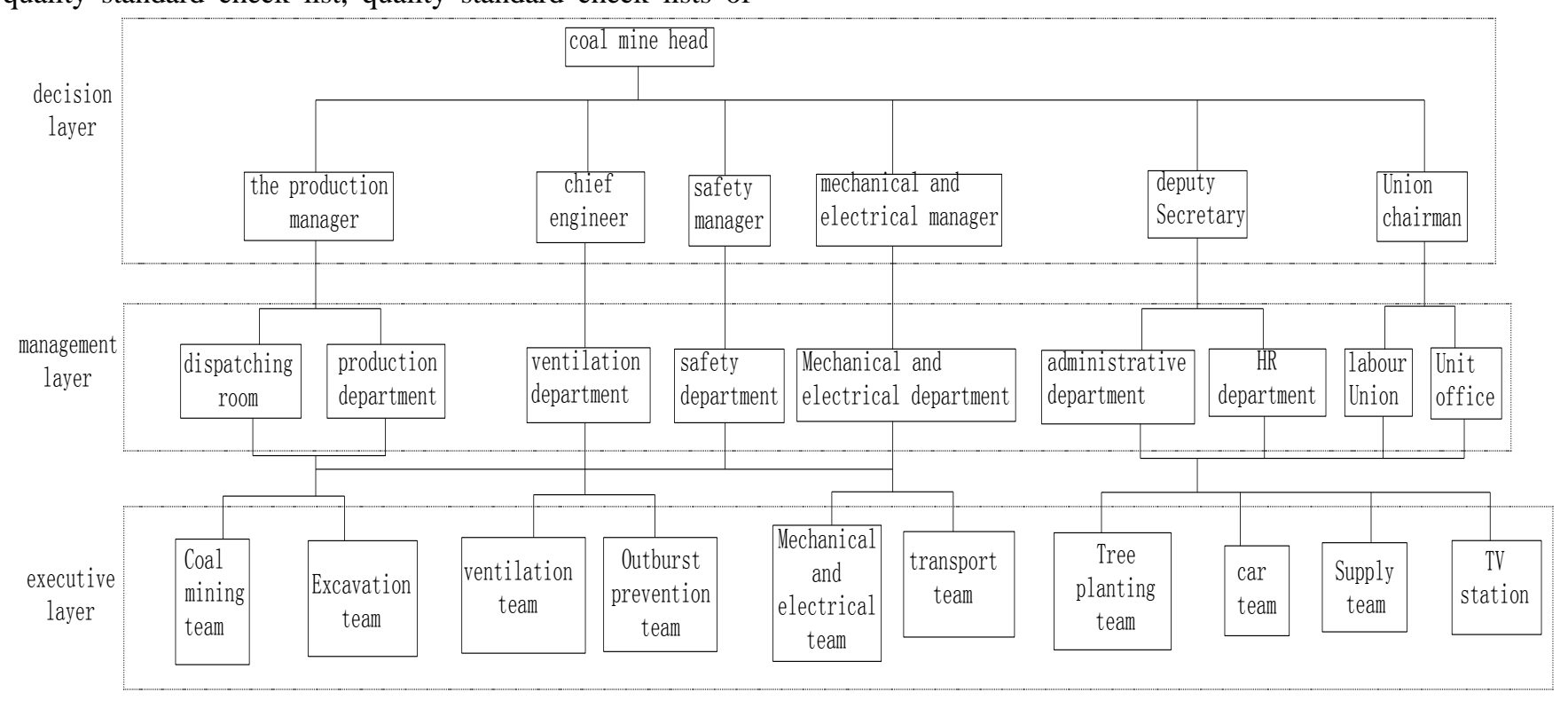

Figure.3. Weijiadi coal mine safety quality standardization system structure diagram

\section{A. Vertical Safety Quality Standardization Construction}

Coal mine vertical safety quality standardization construction is coal enterprise decision layer (Coal mine head), management (Science, team level), executive (group level), namely safety quality standardization construction is a work of full participation.
Decision layer (coal mine head) implement the vision planning, long-term goal formulation, and introduction of relevant norms system, so as to form a strong constraint conditions in the safety and quality standardization construction work. In accordance with the relevant system of safety quality standardization, management (branch, team level) carry out the supervision and management of business 
scope. According to the system specification and standard, implementation layer finish work. The safety and quality standardization process which each task has the task, supervision, management, assessment, and acceptance can be formed. Despite the three responsibilities and requirements are different, but they are interrelated, indispensable. Only under the guidance of the common concept three layers can promote the overall improvement of mine safety and quality standardization construction level.

(1) Decision layer: Weijiadi coal mine decision layer attaches great importance to safety quality standard construction, planning a vision, and the establishment of specialized agencies, and annual, quarterly and monthly plan are set. At the same time, to the continuous deepening of the work and to avoid suspicion of "a frog in a well, behind closed doors", In accordance with the "going out, the introduction of" policy, they organized the whole professional management backbone to the most advanced unit studying each year. At the same time, in order to broaden the staff's seeing and thinking, they also invited experts to mine to give lectures, impart some new ideas, new ideas and new methods to the employees, so that mine safety quality standardization construction work can be developed healthily.

(2) Management layer: Management layer plays a role of connecting link between the preceding and the following in safety and quality standardization construction work, they must recognition decision layer's thoughts and ideas, and convey these thoughts and ideas to the executive level, and in accordance with the corresponding standards and norms supervise and manage the execution of the executive. In the "Internet plus" background, management must keep pace with the times, innovate management, improve service levels, and to adapt to the development requirements of the times, through constantly improving the examination system and the implementation of the work, innovative management mode can be realized.

(3) Executive layer, Executive layer is coal mine team the most grass-roots staff, and direct executor of thought and idea of decision layer, through a deep understanding of the guidance documents, their political consciousness have been raised, the implementation of the standardization of the quality of work have been achieved.

\section{B. Horizontal Safety Quality Standardization Construction}

Wei Jiadi coal mine security horizontal quality standards work is mainly refers to the production process of coal mining, tunneling, machine, transportation, communications, and other various aspects of the system safety and quality standards work.

(1) The safety quality standardization construction of coal mining face. In accordance with the provisions of the mining working face operation instruction and the heavy and difficult work safety technical measures, the working face under the exits are unblocked, coal wall and straight chute situation have detailed records of inspection; hydraulic support can not be dumped, goaf caving is tight, the corner anchors are in good condition.
(2) The safety quality standardization construction of the fully mechanized tunneling face. Including the roof management, roadway molding, material stacking and other aspects of environmental health strict standards, staffs according to the operating rules work, Special types of work carry documents to work, which makes tunneling working face each aspect can be achieved.

(3) The safety quality standardization construction of ventilation specialty. In Weijiadi coal mine, the standard construction work of ventilation involves the control area of the ventilation team, the prevention team, the dispatching and monitoring center, as well as the fully mechanized team and so on.

(4) The safety quality standardization construction of electrical transport system. Including the safe power supply, the power and the wind to stop without a plan, the safe operation of underground electrical and transport equipment, as well as regional environmental health and other aspects.

(5) The safety quality standardization construction of the transportation system. It mainly includes the ground one, two and three belt conveyor safe operation, the area of dust, and the entire system of environmental health and other aspects of the content.

\section{CONCLUSIONS}

(1) Weijiadi coal mine safety quality standardization level has been greatly improved by the application of Deming principle, the mine each profession presents the spiral type to raise the tendency.

(2) By constructing safety quality standardization system of horizontal to edge and vertical in the end, the mine realizes good situation which safety quality standardization is a comprehensive coverage from ground to underground mine, and it's full participation. Safety quality standardization work achieves a comprehensive standard.

(3) With the improvement of people's mind and the level of technology, enterprises pay more and more attention to the work of safety quality standardization, at the same time, safety quality standardization and safety benefit is mutual promotion. Weijiadi coal mine has achieved good social and economic benefits in the process of safety quality standardization construction, which has promoted the enterprise security and the sustainable development.

\section{REFERENCES}

[1] SUN You-xia, LI Xing-dong, LI Jin-liang, "Analysis of Safety Management Model Based on Management Grid Theory", Safety in Coal Mines, vol.44, no.1, pp. 211-213, 2013.

[2] YUAN Xiao-xiang, QU Yong-li, XU Man-gui, et al., "Principle of standardization construction of coal mines safety quality", Journal of Xi'an University of Science and Technology, vol. 31, no.6, pp. 787789, 2011.

[3] LIU Shuang-yue, WANG Juan, WANG Dan, "Evaluation of Safety Quality Standardization in Coal Mine Based on Set Pair Analysis", Journal of Mining \& Safety Engineering, vol.29, no.5, pp. 725-734, 2012.

[4] SHI Honghong, "Management pattern of coal mine based on PDCA", Journal of Liaoning Technical University(Natural Science), vol. 27(Suppl), pp. 272-273, 2008. 
[5] WANG Lu, LI Shugang, CHENG Lianhua, ET AL., "Assessment Index System of Coal Mine Emergency Ability Based on PDCA Model", Safety in Coal Mines, vol.45, no.8, pp. 241-244, 2014.

[6] CHEN Jin, FU Jun-jiang, SUI Yang, "Research on the Construction of Mining Safety Standardization System Based on PDCA Theory", China Safety Science Journal(CSSJ), vol.20, no.4, pp. 49-54, 2010
[7] LIANG Yu-xia, LIU Shuang-yue, WANG Juan, et al., "Development and application of the standard safety quality information management system in coal mining corporations", Journal of Safety and Environment, vol.12, no.2, pp. 187-190, 2012. 